\title{
Some Sociological, Medical and Legislative Views on Video Game Addiction (A Slovenian Case Study)
}

\author{
Jana Goriup - Alexander Arnuš
}

\begin{abstract}
Millions of people worldwide play video games; also in Slovenian post-modern society. Most of them do it for enjoyment, yet a small number of individuals show traits associated with addictive behaviour when interacting with their games. The authors in the article point out that, compared to drug abuse, there exist some more approachable life-related activities that can lead to addiction. They stimulate the excretion of endorphins and lead to the transformation of consciousness. Addiction to video games is an ostensible attempt to satisfy the immanent human need for meaning. The economy of the Slovenian young consumer society inspires it and is based on "learning" of these alienated needs. The modern hyperpragmatic society makes it possible for young people to have a fragmented identity and places them under the pressure of constant choice of (formally open opportunities).

The purpose of this paper is to familiarize the reader with possible causes, clinical signs and methods of treatment of this disorder in Slovenian postmodern society, and explain the reasons why currently no medical textbook in the world contains any information regarding video game addiction. We intend, further, to demonstrate that gaming has become a type of "sport" in certain countries and demonstrate how potentially devastating even this type of addiction can be. The authors present the results of a research, which was undertaken on a sample of 350 individuals, to determine the appearance of indicators of behavioural addiction to video games and their connection with some family factors. They determine that through addiction to video games, post-modern societies have developed an addictive identity.
\end{abstract}

Key words: addiction, video games, risk-reward, parenting, peers, death, leagues, help centers, twelve-step programs.

* Jana Goriup, University of Maribor, Maribor, Slovenia; jana.goriup@um.si

Alexander Arnuš, University of Maribor, Maribor, Slovenia;

alexsg1_rox@hotmail.com 


\section{Introduction}

Addiction is understood as an individual's chronic avoidance of his/her internal conflicts and loosening of the limits of his real life, which is denoted by an intensive and permanent wish and need for either a drug or for a specific activity in order to avoid the existing unwanted condition of his consciousness and to enable an escape from it. Regardless of the kind, cause and form, the addiction can be either physical and/or mental. It is determined by compulsion, loss of control and individual's persistence in such behaviour despite the perception of the bad effects in addictive behaviour. Researchers classify addictions into addiction to drugs and addiction to activity; but nowadays we are coping with addiction to video games, as well. A similar attitude to the means of addiction, concentration on the object(s) of addiction and experience and behaviour of an addict are typical of all kinds of addiction. Even though the intensity and speed of destructive consequences of addiction to activity are slower and less intensive, similar destructive consequences, such as an individual's limited ability to satisfy his needs, unsociableness, alienation from people important for $\mathrm{him} / \mathrm{her}$; financial, material and social self-destruction and in the last stage of addiction, physical collapse of an individual etc. can be noticed.

Addiction is also defined as an on-going use of a chemical substance or the continuous performance of an activity in spite of the long term deleterious effects that such actions entail. It can take on different forms; one can, for example, be addicted to sex, gambling, alcohol, cocaine, heroin, smoking, adrenaline and even physical strain and to video games. When such stimuli are absent, a change of mood can occur and individuals can become preoccupied with it to the point where they can be harmful to others. As a substance is continually used, the body will try to incorporate it into its physiology. This leads to both tolerance (i.e. when the body has accustomed itself to the substance and requires a larger dose to experience the same effect - diminished returns) and withdrawal (the body's reaction to the absence of a substance, which can be lethal).

\section{Some social and medical aspects of addiction to video games}

Ferguson, Coulson and Barnett (2011) in a meta-analytic review of the research, concluded that the evidence suggests that video game addiction arises out of other mental health problems, rather than causing them. Thus it is unclear whether video game addiction should be considered a unique diagnosis. The transition from "normal" behaviour to behaviour denoted by elements of addiction to video games is important for a global analysis of different forms and kinds of addiction. The individual experiences the process of disorder at the subconsciousness level. The process of change is, for him/her, too fast and fluent; the activity itself, to which the individual is often involuntarily exposed, 
conditions the process of change, feeding the need for the frequency of activity and the purpose of addictive behaviour. The individual does not develop his/her addiction to an activity immediately, but through:

- an introductory period (with a constructive use of the activity for personal, social and physical development which is difficult to distinguish from normal behaviour);

- a critical period (from abuse to development of habits, he/she can still control his/her addictive behaviour);

- a chronic period (the creation of habits starts a transition to addiction; finally, the illness of addiction is repeated and seen in negative behavioural patterns, which become independent and permanent).

The individual focuses his/her life only on the addictive activity because of his/her increasing attachment to the means of addiction. As an addict, he/she suffers from the compulsion of constant repetition and an increase of the quantity of a certain activity. Gross (1999, pp. 29-30) stresses the criteria which determine an individual's addiction to video games as:

- the purpose in the use of certain behaviour (escape from reality, change of consciousness),

- deficiency substituted by certain behaviour (concentration, consideration, attention),

- object of avoidance (stress, burnout syndrome, feeling of life's aimlessness),

- frequency of the abuse of a certain behaviour,

- the situation of an individual's life allows his/her abuse to develop (by contentment, slowly/fast, (un)controlled, excessively, ritually),

- the effects of activity on mood (hallucinogenic, stimulants, relaxing),

- physical and mental health (loss of control, compulsion of repetition, increase of the dose),

- signs of abstinence (trying refrain from activity).

Griffiths (2010) proposed that addiction has six components: salience, mood modification, tolerance, withdrawal, conflict, and relapse. Petry et al. (2014) state that APA has developed this and has proposed 9 criteria for characterising gaming disorder:

1. Pre-occupation. Does the individual spend a lot of time thinking about games even when he/she is not playing, or planning when he/she can play next?

2. Withdrawal. Does he/she feel restless, irritable, moody, angry, anxious or sad when attempting to cut down or stop gaming, or when he/she is unable to play?

3. Tolerance. Does he/she feel the need to play for increasing amounts of time, play more exciting games, or use more powerful equipment to get the same amount of excitement he/she used to get?

4. Reduce/stop. Does he/she feel that he/she should play less, but is unable to cut back on the amount of time he/she spends playing games? 
5. Give up other activities. Does he/she lose interest in or reduce participation in other recreational activities (hobbies, meetings with friends) due to gaming?

6. Continue despite problems. Does he/she continue to play games even though he/she is aware of negative consequences, such as not getting enough sleep, being late to school/work, spending too much money, having arguments with others, or neglecting important duties?

7. Deceive/cover up. Does he/she lie to family, friends or others about how much he/she games, or tries to keep his/her family or friends from knowing how much he/she games?

8. Escape adverse moods. Does he/she game to escape from or forget about personal problems, or to relieve uncomfortable feelings such as guilt, anxiety, helplessness or depression?

9. Risk/lose relationships/opportunities. Does he/she risk or lose significant relationships, or job, educational or career opportunities because of gaming?

Taylor (2002, p. 291) among the other factors that significantly contribute to the beginning and development of addiction to video games, stresses the role of a real social situation. It conditions the existence of addiction with its attitude towards addiction to video games. Therefore, the behaviour of the addict reflects the basic assumptions of a society of prosperity and consumption, which Beck (1986, pp. 17-48) described as the "society of risk", in which the causes of addiction lie deep in post-modern society. The strengthening of the power of technical and economic progress promotes the "production of risks". The consequences of the risks of modernization, endanger the natural balance of social developments and the role of the individual in it. For him/her, an escape into "personal well-being" is not strange in such a contradictory society which lacks convincing visions of the future. He/she interprets the addictive behaviour as a compensation for numerous frustrations and as an important source of stabilization for him/herself and society. Realizing that he/she is not capable of understanding the technologically highly-developed objects of his physical environment where it is difficult for him/her to find health inside him/herself and in accordance with natural rhythms: the solution lies outside him/herself.

As postmodern society is alienated and sick, a certain degree of individual pathology is normal; it even helps to sustain the existing social order. Therefore, an individual can share his/her "personal defect" with most representatives of his/her society. Lechler (1990, pp. 9-18) understands addiction to video games as "part of a disturbed ecosystem" which tries to trigger self-cure and find a healthy balance in its totality despite the danger of self-destruction. For Illich (1971, pp. 52-65), even educational-social institutions are based on the uncertainty they produce. As these institutions do not give their users a real experience, they make them dependent on formal certificates of knowledge and talents. The primary goal of teaching the skills needed for life has become lost in 
curricular rigidity and the hierarchy of the educational system. The identity of a young person is developed by something external - the pattern of addiction, acknowledging certificates and marks more than research and learning for life. Therefore, it is important that, besides the family and social relations, education offers and develops basic social experience that determines the character of interactions with the social and institutional environment.

\section{Possible causes, signs and symptoms of addiction to video games}

Technology has been taking the lives of the Slovenians by storm and in the last two decades has given birth to a new type of addiction - video game addiction.

Video game addiction is a relatively new concept with a myriad of variables. Because people of both sexes, all ages and religions, play video games. It is very difficult to identify the actual precipitating factors involved in the process of becoming addicted to a game. The American Psychiatric Association has consequently denied proposals to include this condition in their Diagnostic and Statistical manual of Mental Disorders several times.

The discussion that follows is thus a subject of on-going investigation and should not be construed as fact or a definite guide to the topic at hand.

\subsection{Possible causes}

Every game contains various elements with which the player works in order to reach a certain goal. This is usually accompanied by a reward. The reward, however, is commensurate with the effort, and indeed, the risk that was involved in the work process. This is called the risk-reward factor and it means that the greater the risk the person performing a task takes, the greater a reward he/she may expect to be given when it is completed. It has been discovered that video game companies often use a phenomenon called the variable rate of reinforcement when developing their games. Its foundation is a very simple experiment: We take a hungry rat and place it in a cage. In the said cage there is a food dispenser with a button that gives out treats randomly, when pressed. Once the rat realizes this, it vigorously starts pressing the button until enough food comes out to sate its appetite.

The same concept applies to humans in relation to video games. The result of this is that some individuals become insatiable and develop the compulsion to obtain every reward the game has to offer in the shortest time frame imaginable. This leads to massive daily time expenditure, which in turn hampers their responsibilities, most notably those related to work and school. The relationship between gaming and work/school is reciprocal. Overzealous gaming can either cause failure at work or in school, or be the result of an unsuccessful life. In order to compensate for the lack of success, people tend to preoccupy themselves with an activity that will obfuscate the reality of the situation. Video 
games offer the ideal environment to do so because their equal playing field gives everybody a chance to be successful.

We must not ignore the influence that types of games can have on the consumer. They can roughly be described as:

- multiplayer games, where several people play against or with each other via the internet, and

- single player games, with a pre-programmed sequence of events for a single player.

Online gaming has been rapidly increasing with the ever greater global access to broad-band internet. Multiplayer games give players the opportunity to develop friendships with others and once a friendship is established, you may want to stay in touch with that person and that may compel you to keep on playing. Some people have even started families and had children with players they had met online.

A special type of multiplayer game, called a Massively Multiplayer Online Role Playing Game, revolves around the progression of your character or avatar, and players, after investing much time and money in it, do not want to abandon everything that they have worked for. This is particularly true of World of Warcraft, a game by Blizzard Entertainment, which is currently played by approximately 10.5 million people worldwide. They were provocatively asked about their stance on addiction and their reply was the following: "Our games are designed to be fun, but with like all forms of entertainment, day to day life should always take precedence. They also contain practical tools, which assist players with monitoring their play time."

In addition to simple enjoyment, playing games represents a means of earning money. With the right contract on YouTube, you can earn up to $2 \$$ per one thousand views of your video. A player may upload several videos per day and each can fetch hundreds of thousands of views. This can lead to a very large sum of money landing in their pockets. And as far as motivators go in our postmodern society, money is easily among the most powerful ones. Money talks!

Most experts across the world dismiss video game addiction as just another media amalgamation, but those who understand the seriousness of some people's condition have put forth several risk factors, which may or may not play a role in the onset of video game addiction. These include aggression, impulsiveness, a general desire for new and unique experiences, depression, strict parenting and low self-esteem. There is evidence to suggest that male players are more addiction-prone than women.

Spending a lot of time behind the computer invariably leads to a sedentary lifestyle. This can lead to poor development in children and various orthopaedic problems in adults. Prolonged gaming can lead to tiredness, sleep disorders, anxiety and irritability. People tend to let themselves go, neglect their hygiene, postpone meals, eat junk food, profusely gain or lose weight, all of which contributes to a general decline in health. Although not irrefutably proven, there 
have been links established between long-term exposure to monitors and impaired vision.

\subsection{Extreme cases}

Online games are particularly popular in South Korea, where as many as $85 \%$ of the population have access to broad-band internet. As a national sport, Tae Kwon Do has been joined by Star Craft as a so-called eSport, which has its own tournaments. Those who compete at these events spend up to 150 hours a week playing, which is equivalent to 21 hour every day! This is illustrated by the fact that there are internet cafés present on every street in which youngsters hang out in the evenings instead of spending quality time with their friends, peer groups or family.

When gesticulations were compared between those watching TV and those playing video games, a marked difference was noted, especially in the effect that games had on the central nervous system. A boy is reported to have lost the blinking reflex entirely and gave the appearance of crying.

The concept of lethality is inherent in addiction and video game addiction is no exception. There have been roughly 16 cases reported across the world, where people died as a result of their over-attachment to games. They stem mainly from the United States, South Korea, Taiwan, China and Vietnam. The major cause of death is cardiac arrest, brought on by dehydration. Earlier this year, an 18 year old boy died in Taiwan after a continuous 40 hour gaming session. Not all deaths have been self-inflicted. A father let his twins drown in the tub, while he/she was playing Game Boy Advance in the adjacent room, and a mother shook her baby to death because its crying impeded her FarmVille exploits. A mother found her premature end at the hands of her own son after having confiscated his Play Station.

It is events such as these that have prompted various countries to address the issue more seriously and promote the foundation of various help centres.

\subsection{Prevention and treatment}

People who show signs of video game addiction come across similar problems as food addicts.

As an addict to food cannot stop abusing food and procedures connected to eating, even though he/she wants to, people addicted to video games cannot stop playing. An addict does not eat when he/she is hungry and lonely, but when is emotionally unsatisfied. He/she spoils the natural feeling of hunger and loneliness. Food and video games are surrogates for internal balance.

Just as food is an indispensable part of our lives, we interact with computers on a daily basis and it is practically impossible to do away with them entirely. The fact that conventional treatment does not recognize this as a disorder, complicates matters in as much as there are no specified and tested treatment programmes available for people to enlist on. Some countries, namely the 
Netherlands and the United States, have listened to the pleas and arguments presented by some experts, which has led to the establishment of help centres in which people can seek help in a form they refer to as "Twelve-step programs". These include acceptance, rectification of one's mistakes and help from those who have found themselves in a similar situation.

The Chinese have taken this a step further with a more Orwellian approach, limiting the available play time to three hours daily as well as requiring personal identification before being permitted to play. Minors are automatically advised to do some physical exercise after a three-hour playing binge.

The South Korean government has built specialized camps for minors suffering from video game addiction, to which parents can send their children. One such child was reported saying, "Playing games was fun and I had nothing else to do."

This epitomizes the role of parents, when it comes to preventing any kind of idiosyncratic behaviour. It is their responsibility to observe their offspring during their formative period and to act immediately and appropriately, should any kind of abnormality present itself.

The quality of interactions and the existence of someone to confide in within the family and educational programmes have proved very important. Therefore we emphasize the possibilities within school subjects and educational programmes, where the pupils can not only be informed but also educated about the dangers of behavioural addiction to video games.

A lecture can be given by a teacher, medical staff or a therapist and organised as a discussion after the introductory presentation which could be an article read, a film watched, working on statistical data connected to the topic, or an organised exhibition about the topic. Students can also work in groups; each group working on one form of addiction and presenting it in the final part. The students can also record a short conversation (on tape, video, film) with different participants (a cured addict, a physician, parents) as a preventive form of education.

\section{Slovenian youth and addiction to video games}

Slovenian youth is a special generation and a more or less formed social group with an intensive experience of the quick tempo of social, cultural and technological change; by taking part in mass education which distinguishes them from other generations and defines them as a subculture. It postpones integration into the sphere of work and consequently the division of social power; even though they are physically mature, they use all their energy for education which shifts away the social acknowledgement of maturity and causes discrepancy between their psycho-physical abilities and their social status.

The problems of the lack of communication in the family, non-personal relationships in the process of education, the difficulty in growing up, the 
experience of emptiness of social values, effectively combine to create a motivation to seek addictive activities. As the addiction represents a uniform problem, the choice of means of addiction is of secondary importance. Addictions to video games connected to Slovenian youth show peculiarities that are related to specific individual dispositions and social significance of individual means of addiction to activity. The most frequent addictive to activities follow:

\begin{tabular}{|c|c|c|c|c|c|c|c|c|c|c|c|}
\hline & 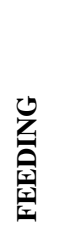 & 氠 & 党易 & 岂 & 资 & 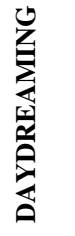 & 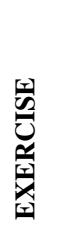 & 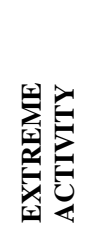 & 聜 & 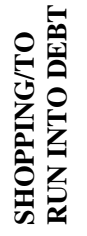 & 空 \\
\hline FEEDING & 1,000 &, 286 & & ,238 & &, 418 & & & & 290 & 561 \\
\hline INTERNET &, 286 & 1,000 & &, 185 & & ,282 & & ,272 & ,299 & ,234 & 573 \\
\hline $\begin{array}{l}\text { GAMBLING } \\
\text { AUTOMAT }\end{array}$ & & & 1,000 & & 294 & & & ,190 & 355 & & 375 \\
\hline LEARNING & ,238 &, 185 &, 185 & 1,000 &, 222 & ,308 & & & & 226 & ,551 \\
\hline RELIGIOUS & & & & ,222 & 1,000 & ,275 & & & ,267 & ,195 & ,409 \\
\hline DAYDREAMING & ,418 & ,282 & & ,308 & 257 & 1,000 & & ,214 & ,379 & ,344 & ,711 \\
\hline EXERCISE & & & & & & & 1,000 & ,241 & & & ,208 \\
\hline $\begin{array}{l}\text { EKSTREM } \\
\text { ACTIVITY }\end{array}$ & & ,272 & ,190 & & & ,214 & 242 & 1,000 & 203 & & ,447 \\
\hline THEFT & & 299 & ,335 & & ,267 & 379 & & ,203 & 1,000 & ,235 & 521 \\
\hline $\begin{array}{l}\text { SHOPPING/TO } \\
\text { RUN INTO DEBT }\end{array}$ & ,290 & ,234 & & ,226 &, 195 & ,334 & & & 235 & $\begin{array}{r}1,00 \\
0 \\
\end{array}$ & ,494 \\
\hline $\begin{array}{l}\text { GENERAL } \\
\text { DEPENDENCE }\end{array}$ & ,561 & ,573 & ,375 & ,551 & ,409 & ,711 & ,208 & ,447 & ,521 & ,497 & $\begin{array}{r}1,00 \\
0 \\
\end{array}$ \\
\hline
\end{tabular}

Empirical data used in this Table 1 form a part of a wider research carried out between 1 February and 1 October, 2010.

The consequences are shown in increased delinquency and crime, bad family relations and decreased school efficiency, problematical behaviour. The addict's characteristics are: decreased self-respect and possibilities for problem solving, increased degree of depression and suicidal behaviour, neglecting physical and mental needs, cardiovascular disturbances, undernourishment, too much body fat, lower life expectancy (Derevensky and Gupta, 2000, pp. 226-255).

\section{Empirical part}

Addiction to video games has become more intensive with easier and increased access to internet technology as an excessive use of the internet and spending time without clear goals is typical. A virtual compensation of real social relations is typical of the young who experience lack of appropriate family communication and of parental and peer attention. As the source of addiction is 
based on different aspects of internet video games use (typing, communication, contents, social activities), it is difficult for addicts to define the exact time of use as their perception of time is disturbed (spending up to 40 hours a week "online"). The longer the time since the first contact with internet is, the disposition to use the internet more and more increases. This addiction is often connected with depression, disturbed control of impulses and low self-respect. Because of school obligations and work needs, medical treatment is difficult.

As for the purpose of this article, a survey was conducted; 350 individuals responded to the survey, 140 being male and 210 female. The age varied from 16 to 38 years of age with an average age of 29.5 years. The goal of the research was to find out if they are (not) addicted to video games, with the emphasis on the question whether this current form of addiction provided them with enough knowledge and skills to perform their lives to their best abilities. For the purpose of the research our initial assumption was that most participants would not be familiar with the idea of video game addiction. Further we supposed that:

1. Most people are unaware of video game addiction.

2. Time spent is a relative criterion for evaluating video game addiction

3. The principal role of preventing video game addiction lies with the parents. In order to test the assumptions, we carried out an online survey, consisting of multiple choice and open questions. We asked them: how familiar they were with addiction; whether they played video games themselves; about the reasons some individuals spend a lot of time playing video games; how much time would one have to spend playing video games per day to classify as an addict; about the most vulnerable population to be effected of video games; about the signs and (no) current medical diagnosis of video game addiction, about professional gaming leagues and events similar to regular sporting tournaments etc.

The purpose of question No.1 was to see how familiar the respondents were with the issue of addiction in general. These were the responses:

\section{Figure 1}

How familiar are you with addiction?

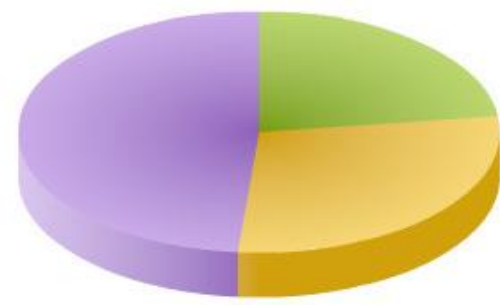

I have heard of it. (22.9\%)

I know a lot about it. (28.6\%)

I am aware of it and wish more people were. (48.6\%)

ive never heard of it. $(0 \%)$ 
The results provide an ample basis for discussion because everybody has at least heard of addiction, therefore the concept can be further expanded on. We wanted to find out how familiar the participants were with video game addiction as a problem.

\section{Figure 2}

Did you know that some people show signs of being addicted to their video games?

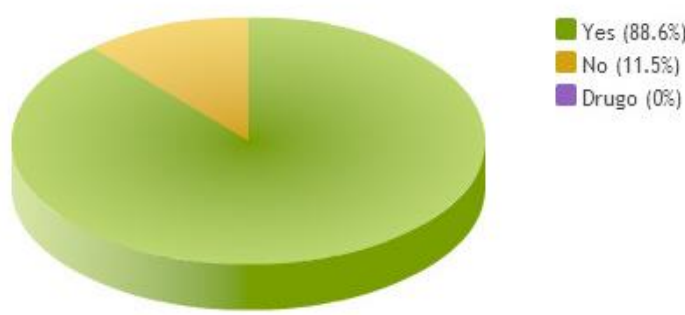

These results were somewhat of a surprise as, based on our first assumption, most participants would not be familiar with the idea of video game addiction. They allow us to assume that more people are aware of the issues some people face than previously stipulated, which should, if more research is conducted, give rise to a more concrete picture of video game addiction.

\section{Figure 3}

$$
\text { Do you play video games yourself? }
$$

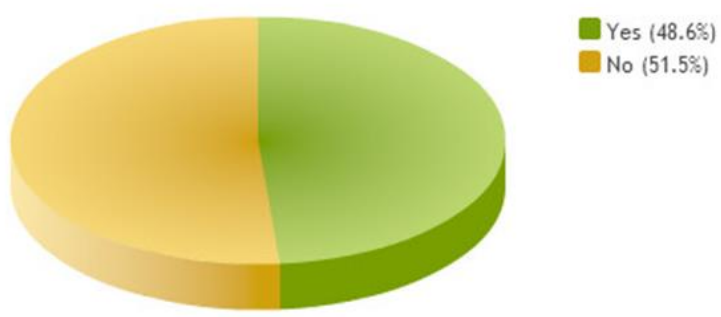

We were witness to a quite large disparity, as the results were almost evenly split between "yes" and "no". The vast majority of those who do play video games do it for fun, a few declared it being a hobby, while someone said it gave them the "illusion of spending quality time". Because the prevailing reasons for playing games are fun and hobby-like characteristics, we could conclude that playing video games is a hobby-equivalent activity, like sports, art or music. Those of us who dabble in any of these like to do so on a regular basis as it represents something we enjoy doing. Therefore it is possible to argue that it is unfair to 


\section{Acta Technologica Dubnicae \\ volume 4, 2014, issue 1}

treat someone who plays video games regularly as an addict, because it is something they enjoy doing and treat as a hobby. Those who do not play video games, according to the survey, either lack the time for it or are not interested in, do not like video games, or have other activities they prefer doing.

Because the reasons for playing games present a stalemate in our attempt to analyse video game addiction, we focused on time spent and the participants' views of it.

\section{Figure 4}

Do you believe time spent is a relevant criterion in diagnosing this condition?

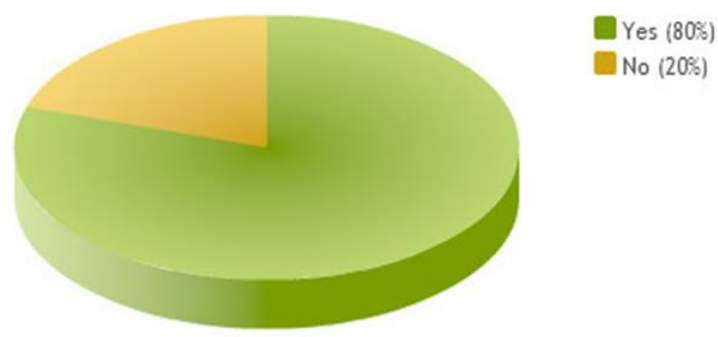

The responses were almost one directional, as $80 \%$ declared they considered time spent to be a relative criterion when diagnosing video game addiction, thus supporting our second hypothesis. We, of course, wanted to know how much time they considered to be a telling sign of addiction and the answers were varied.

\section{Figure 5}

If your answer to the previous question was YES, how much time would one have to spend playing video games per day to classify as an addict in your opinion?

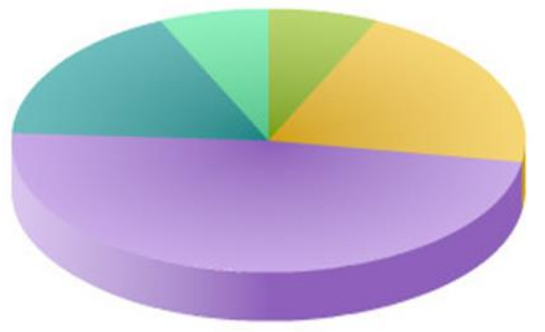


Almost half of those asked believed that spending between 4 to 6 hours is indicative of video game addiction, whereas others considered 1 hour per day and as many as 7 hours per day as evidence if addiction. We also allowed participants the option of providing their own answers, one of which was $10+$ hours and an even more extreme case of 15 hours or more per day.

As seen by the results, there is no consensus as to how many hours one would have to spend playing video games on a daily basis to qualify as an addict. This is one of the major problems preventing video game addiction from being considered seriously by the medical community. Video game addiction is an excessive or compulsive use of video games, which interferes with a person's everyday life. Video game addiction may be seen in compulsive game-playing; social isolation; mood swings; diminished imagination; and hyper-focus on ingame achievements, to the exclusion of other life events.

When looking at this phenomenon from another perspective, through interviews with gamers who were addicted to a MMORPG but have quit playing, it is believed that the multiple reasons causing gamers to leave their game can reflect some more aspects of online game addiction. Some said they did not play games daily, others spend 1 hour, some 3 hours, someone said 10 minutes, while another person said he/she could spend up to 12 hours daily if the game he/she was playing was brand new and enjoyable. Those who do not play games on a daily basis, tend to spend more time playing them on the days they actually do play.

We must not discard the $20 \%$ who said time was not a factor. Their opinion is, according to the survey, that the relationship to the game is the real defining characteristic. They supported this by saying that if you manage to go about your duties (school, work, social life, family) successfully while playing games, the actual time spent doing that does not matter.

We must also allow for another possibility. Addicts try to hide their idiosyncratic behaviour by employing many strategies and for many reasons. So their "normal" routine does not necessarily indicate the absence of addiction.

This further epitomizes the difficulties faced when trying to accurately evaluate the concept of video game addiction.

We checked also our third assumption which was that the principal role of preventing video game addiction lay with the parents. 


\section{Figure 6}

Who would you mainly blame if a child or adolescent started showing signs of video game addiction?

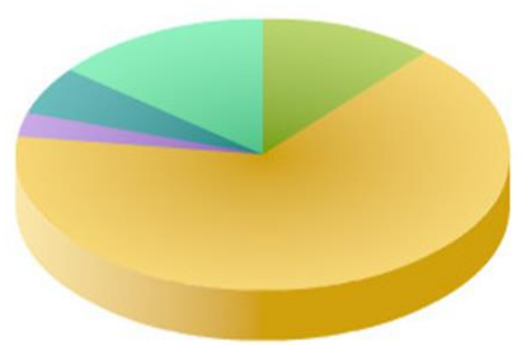

The child. (11.5\%)

Their parents. (65.8\%)

The video game developer. $(2.9 \%)$

Their peers. (5.8\%)

Drugo (14.3\%)

The majority of the responses were supportive of our final assumption, with almost two thirds saying they believe the parents should keep a watchful eye during their children's formative period and nip any addiction in the bud. A select few chose to blame the young, however, youth cannot be held responsible, because they lack the experience and the expertise to help him/herself should he/she develop a continuous urge to play games. Other responses included both parents and peers and a fraction chose to blame the video game developer. As presented in the theoretical part, there are some mechanisms the developers allegedly put into their games to make them more addictive. We asked the participants whether they believe this is true and these are the responses.

\section{Figure 7}

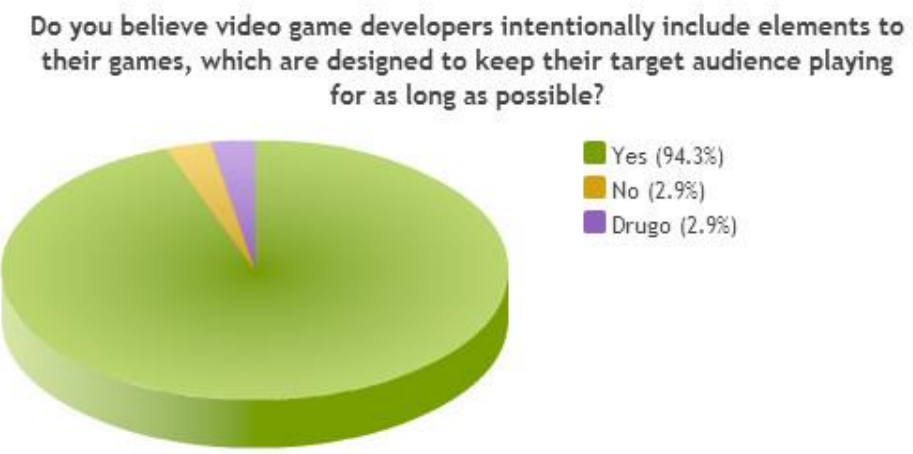

94.3\% out of asked believe that these elements are intentionally put in, but they do not believe they are the main cause, as illustrated by the previous pie chart. 


\section{Conclusion}

The study yielded surprisingly positive findings, especially those related to our first assumption and we should see considerable progress in this area in the coming years. We have learned that many people play video games, as half of our participants declared themselves as gamers. The reasons for playing games vary from fun, hobbies and killing time. Time spent, however, has been shown to be, in the eyes of most participants, a relevant factor in diagnosing video game addiction, while those few who argued that time was not relevant, presented some strong arguments pertaining to their relationship to the game. And yet this relationship can be a mere mask. Even though time spent is considered by many to be relevant, they do now show any consistency as to how much time is relevant in the diagnosis. Therefore, further study and research is warranted, perhaps analysing similarities between time spent on medically recognized addictions and time spent playing computer or console games.

The life-style of the young in society increasingly reflects the accumulation of all life experiences. Despite the insecurity about the future, in their attempts to preserve a sense of meaning and personal integrity, the young often react wrongly when they escape to the world of stupor and addiction. The role of the school and the family is to help the youth on their way of recognising and curing the addiction. An important change towards a better understanding the problems of the young has been made in education in the period of independence.

Disharmony between loosening disciplinary standards and demands can be noticed in schools, being basic educational institutions. These undermined its authority as it can no longer promote the individual and develop his/her optimal abilities and prepare him/her for life in a complicated complex of life circumstances. However, school has to give the individual the feeling of security and to create creative internal standards with clear demands which will distinguish him/her from the others after the work has been done.

\section{References}

BARLE, A. and GORIUP, J. Chapters of Sociology of Education: an overlook of contemporary sociological studies, perspectives and concepts. Koper: Faculty of Management, 2006.

BECK, U. Risikogesellschaft. Auf dem Weg in eine andrer Moderne, Suhrk. Frankfurt am Main: amp Verlag, 1986.

BRANDT, M. L. Video games activate reward regions of brain in men more than women. Stanford study finds. Stanford: Stanford University School of Medicine, 2008. Available from:

http://med.stanford.edu/news_releases/2008/february/videobrain.html.

DEREVENSKY, J. and GUPTA, R. Prevalence estimates of adolescent gambling. Journal of Gambling Studies, 2000, 16, 33-45. 
FERGUSON, C. J., COULSOM, M. and BARNET GRIFFITHS, J. Video game addiction. Journal of Psychiatric Research 2011, 45 (12), 1573-1576. Available from: http://www.tamiu.edu/ cferguson/Video\%20Game\%20Addiction.pdf.

Faiola, A. When Escape Seems Just a Mouse-Click Away - Stress-Driven Addiction to Online Games Spikes in S. Korea. Washington Post Foreign Service, 27 May 2006. Retrieved 25 June, 2007.

GRIFFITHS, M. Online video gaming: what should educational psychologists know? Educational Psychology in Practice, 2010, 26 (1), 35-40.

GROSS, W. Sucht ohne Drogen. Frankfurt am Main: Fischer Taschenbuch Verlag, 1999.

GORIUP, J. Civic culture. Ljubljana: Državna založba Slovenije, 1999.

HAGEDORN, W. and Young, T. Identifying and Intervening with Students Exhibiting Signs of Gaming Addiction and other Addictive Behaviors: Implications for Professional School Counselors. Professional School Counseling, 2011, 14(4), 250-260.

ILLICH, J. Deschooling Society. New York: Harper \&Row, 1971.

LECHLER, W. H. Nicht die Droge ist's, sondern der Mensch. Burg Hohenstein, 1990.

PETRY, N. et al. An international consensus for assessing internet gaming disorder using the new DSM-5 approach. Berkeley Parents Network, 2014.

TAYLOR, C. Z. Religious Addiction: Obsession with Spirituality. Pastoral Psychology, Human Science Press, 2000, 50/4, 237-245.

ULE, M. Socialna ranljivost mladih. Maribor: Urad RS za mladino, Aristej, 2000.

www.techaddiction.ca/video_game_addiction.html\#.UIhCPsXjTHQ www2.canada.com/victoriatimescolonist/news/story.html?id=f0ee0f84-2e8046db-a1f7-1709c9a050a0

www.v3.co.uk/v3-uk/news/1990058/chinese-gamer-dies-day-session www.nydailynews.com/news/national/kendall-anderson-16-killed-mom-clawhammer-playstation-court-article-1.139414 www.techaddiction.ca/video-game-addiction-risk-actors.html\#.UIhEKMXjTHQ http://en.wikipedia.org/wiki/Video_game_addiction 